\title{
MODELING AND OPTIMIZING THE PARAMETERS OF CONDENSERS IN SPLIT TYPE ROOM AIR CONDITIONERS
}

\author{
Rahatul Hasan', Md. Khairul Bahar', Md Noor A Alam², Md Yasin Ali ${ }^{2}$ \\ and M.A.A. Shoukat Choudhury ${ }^{1, *}$ \\ ${ }^{1}$ Department of Chemical Engineering \\ Bangladesh University of Engineering and Technology, Dhaka, Bangladesh \\ ${ }^{2}$ Elite Hitech Industries Ltd \\ Plot 6613, Korpai, Burichong, Cumilla 3500, Bangladesh
}

\begin{abstract}
Split type room air conditioners (RACs) are very common nowadays. In Bangladesh, RAC manufacturers employ trial-error prototyping techniques in their design to increase the efficiency of RACs and the profitability of the plant. Computer modeling can be a great help to reduce the cost in the R\&D stage to find the optimum design of RACs. In this study, modeling of heat transfer in the condenser of split type RACs employing the techniques of Computational Fluid Dynamics (CFD) was performed. To reduce the computational load the geometry was divided into small sections and geometric symmetries were also taken into account. For the simulation, the geometry and other relevant data were set in such a way so that they commensurate closely with real industrial data. An example data set for validation of simulation results were obtained from an AC manufacturer company, Elite Hitech Industries Ltd. The geometry was built using meshing techniques. Copper and aluminum were selected as materials for tubes and fins, respectively. R-22 was chosen as the refrigerant. Heat transfer and fluid flow were modeled using non-isothermal flow in a multi-physics environment. The main assumptions employed are laminar flow, extra coarse mesh size, constant air inlet temperature, perfect insulation between system and surroundings, and thin layer fins. The temperature distribution and heat transfer efficiency in the condenser, the impact of different refrigerant flow arrangements in the tubes have been studied in detail. This study leads to the finding of efficient refrigerant flow arrangements from the viewpoint of maximum heat transfer.
\end{abstract}

Keywords: Room Air Conditioners, Condensers, Refrigerants, Heat Transfer, Fluid, Flow Arrangement

\section{Introduction}

Split type air conditioners (SACs) are widely used in residential and commercial building and they are very popular due to their flexibility and simplicity. They consume a very high amount of energy to maintain indoor temperature in a comfortable zone [1][2]. So, improvement of energy efficiency of room air conditioners has a significant importance from engineering perspective. This can be performed experimentally or computer simulation. As experimental set ups are expensive and more time consuming, developing through modeling and checking the model data with real life has been more popular route now a days. SAC has indoor and outdoor unit. In both indoor and outdoor units fin and tube heat exchanger plays a very important role [3]. The outdoor unit has a significant effect on the airconditioner performance
[2]. If the on-coil temperature of an outdoor unit is raised by $1^{\circ} \mathrm{C}$, the coefficient of performance (COP) of the air-conditioner drops by around 3\%[4]. So, the efficient design of outdoor condenser unit has quite importance for RAC.

Avara et al.[2] used a CFD code to calculate the effect of distance from the supporting wall on the entrance air temperature and on the on-coil temperature of condenser installed between two walls. They also considered condenser installed on the roof, the effect of installation height of the condenser from the finished roof on on-coil temperature is investigated and the minimum recommended height of installation also was determined.

Z. Yang et al.[5] conducted an experiment on the explosion characteristics in the indoor and outdoor units of a split air conditioner using the R290 ( Propane) refrigerant considering the environmental impact of the currently used refrigerants. R290 is not 
expected to do significant damage to the indoor and outdoor units.

\section{Nomenclature \\ SAC split air conditioner \\ RAC room air conditioner \\ CFD computational fluid dynamics \\ COP coefficient of performance \\ $\mathrm{Cp} \quad$ specific heat capacity $(\mathrm{J} / \mathrm{kg} \mathrm{K})$ \\ $\rho$ density $\left(\mathrm{kg} / \mathrm{m}^{3}\right)$ \\ $\mu \quad$ dynamic viscosity $\left(\mathrm{Ns} / \mathrm{m}^{2}\right)$ \\ $\mathrm{k}$ thermal conductivity $(\mathrm{W} / \mathrm{m} \mathrm{K})$}

J. Sun et al.[6] analyzed outdoor unit noise reduction by fan geometry modification with the refined numerical and experimental approaches. G. Ding et al.[7] also worked noise reduction for outdoor unit.

N. Mendes et al.[8] modeled empirically four room air conditioners in order to predict the total cooling capacity, the sensible cooling capacity and the Energy Efficiency Ratio (EER) of each appliance in various environment psychrometric conditions and found rotating compressor can save $17 \%$ energy than reciprocating for same conditions.

W.L. Lee et al.[9] experimented the advantage of water cooled air conditioner over air cooled air conditioner and concluded water cooled will give better performance in subtropical regions.

G. Zhou et al.[10] This paper experimentally investigated experimentally the system performance of a split-type air conditioner matching with different coiled adiabatic capillary tubes for HCFC22 and HC290 and found parallel capillary is better than a single capillary. Also, HC290 is better but it is flammable.

T.T. Chow et al.[11] did a CFD analysis for models to evaluate energy performance and effectiveness of various condenser layout scenes under steady state condition.

X. Jin et al.[12] predicted and proposed a model for variable refrigerant flow AC combined with outdoor system. The simulation of the model was done and found better performance than traditional AC.

Y.H. Yau et al.[13] studied the performance of SAC depending on the climate temperature change and concluded that $1^{\circ} \mathrm{C}$ rise in outdoor temperature will drop $2 \%$ COP.

T.T. Chow et al. [4] also numerically analyzed the placement of condensing unit in low rise residence for five different building schemes.

C.J.L. Hernes et al.[14] proposed a model and simulated this for 2.5 ton residential SAC and compared it with experimental data.
S.A. Nada et al.[15] put installation guidelines for optimum arrangements of the outdoor units in building shafts.

Moukalled et al.[16] developed a 3D CFD model for an entire rooftop $\mathrm{AC}$ unit. He predicted simultaneously temperature, velocity and humidity distribution of flowing air. This whole model required a very high computational load and cost but the researchers found a reliable model which gives very precise results.

To get better performance and understanding 3D CFD modeling can be very useful. Air conditioners can be modeled entirely with a very high computational capacity. Most of the cases it is studied as separate part. In this study, a 3D CFD modeling of the outdoor condenser was performed, which plays a very important role in the overall AC performance. To cope up with the huge computational load of 3D modeling, the whole work is done by making symmetric sections of an industrial 1.5 ton $\mathrm{AC}$ outdoor condenser. The condenser heat duty is the sum of the indoor heat duty and the compressor heat duty. So, for a 1.5 ton $\mathrm{AC}$ condenser heat duty will be higher than 1.5 ton or $5.275 \mathrm{~kW}$. In this study, Heat transfer profile and other necessary profiles were analyzed. It is also possible to compare various refrigerants for the various structures and their performance and optimize all the factors.

\section{Modeling details/ Methodology}

Nowadays CFD modeling has become a research and design tool [17]. For the current CFD 3D model some assumptions were made to minimize the computational complexity and resolve the problems of high computational load.

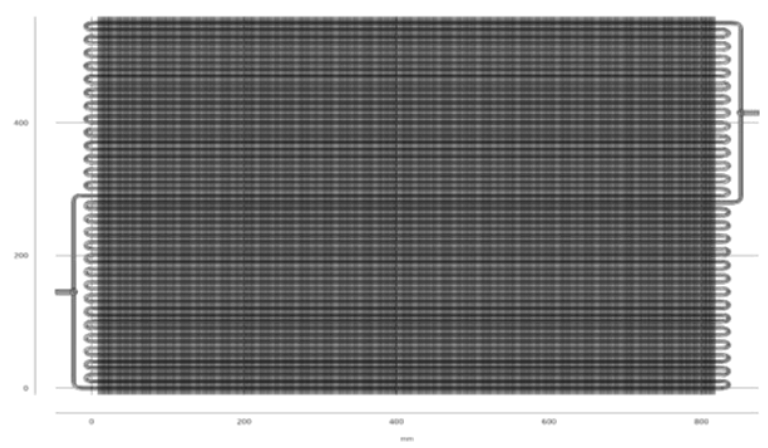

Fig. 1: Geometry of the condenser

The description of an industrial condenser was taken from a local air conditioner manufacturer company. Geometry of the condenser simplification Fig. 1. Air inlet temperature at condenser was taken as $35^{\circ} \mathrm{C}$. The air flow was taken $115 \mathrm{~m}^{3} / \mathrm{h}$ for each section and considered as laminar flow. R-22 was the 
refrigerant in the condenser coil flowing at $1.8 \mathrm{MPa}$ and initial inlet at $90{ }^{\circ} \mathrm{C}$. So, the properties of R-22 taken was of $1.8 \mathrm{MPa}$. The heat exchanger had two identical sections are shown in Fig.01. In this model, the two sections were considered to be uniform to reduce computational load, cost and time. The total refrigerant flow in these sections was assumed equal as the refrigerant is flowing at a very high pressure. So, the gravitational effect for the lower and upper sections can be ignored. The refrigerant flow in both sections was $0.0155 \mathrm{~kg} / \mathrm{s}$.

Fig. 2: Section view

The complete geometry was divided into 14 identical geometrical part (as shown in Fig. 2) with 7 in each section to further decrease the computational load and overcome hardware shortcomings.

An average density was taken for mixed gas and liquid refrigerant flow to avoid the complexities involved with two-phase flow. Each of the seven sections has different average density according to quality of flow. As the refrigerant went along the tubes, it cooled down from its superheated temperature to the saturation temperature and eventually to subcooled temperature. So, the quality and the density of the refrigerant increases continuously as it gets cooled.

The saturation temperature of R-22 was taken as a range from $51{ }^{\circ} \mathrm{C}$ to $46{ }^{\circ} \mathrm{C}$ considering it as saturation zone. For the simplicity, the latent heat for refrigerant was taken by the help of increased specific heat capacity $(\mathrm{Cp})$ with a rectangular step in the saturation zone. To reduce the computational load of the solver process, only the tubes and the fins were modelled as solid parts because of their importance on heat transfer performance. Tubes were made of copper and fins were made of aluminum. Ideal thermal contact was assumed between them.

The heating effect of R-22 from the condenser's pipes was applied to the fins. The other solid domains such as the shell of the section and the fan, were modelled as adiabatic walls assuming that these regions' heat transfer effects were not important for the CFD model, although their effects on flow conditions were considerable. Boundary conditions were determined according to the conditions provided by the company. Tubes and fins were assumed as thin layer and their respective thickness was given as input. This assumption reduces the solver computational load to a great extent. Also, the difference of results between considering thin layer and not a thin layer is too less to neglect. Radiative heat transfer was assumed negligible as the heat exchanger is not operating at much higher temperature.

As mentioned earlier air domain was considered uniform and steady flow of air $115 \mathrm{~m}^{3} / \mathrm{h}$ was considered for each of the 14 sections for simplicity though air flow will be maximum at the front of the fan of the condenser. Yet because of the compact design of fin and tube heat exchanger (FTHE) air flow will be interrupted and can be considered closely uniform throughout the FTHE. The air's thermo-physical properties such as density ( $\rho)$, specific heat $(\mathrm{Cp})$, dynamic viscosity $(\mu)$ and thermal conductivity $(\mathrm{k})$, were taken at $1 \mathrm{~atm}$. Extra coarse tetrahedral mesh was used with maximum element size of $8.4 \mathrm{~mm}$ and minimum element size of 2.72 $\mathrm{mm}$ to further reduce solver computational load. Tube diameter $5 \mathrm{~mm}$ with $0.13 \mathrm{~mm}$ thickness. Fins were $12 \mathrm{~mm}$ wide and thickness is $0.09 \mathrm{~mm}$. Fin to fin distance was $1.5 \mathrm{~mm}$.

The iterations of the three dimensional steadystate analyses were continued until the residuals reached $10^{-3}$ and the domain imbalances dropped below 0.001 . For this model heat transfer in solids and fluids module and Computational Fluid Dynamics module with Non-Isothermal flow coupling were used. The CFD module is used to compute the velocity and pressure fields for the flow. The Navier-Stokes equations for conservation of momentum and the continuity equation for conservation of mass are solved. Nonisothermal Flow Multiphysics coupling is used to simulate fluid flows where the fluid properties depend on temperature. Heat transfer in solids and fluid module includes conduction and convection heat transfer.

\section{Results and discussions}

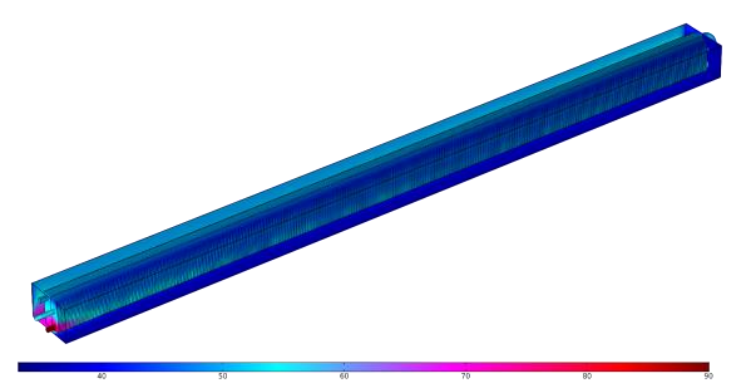

Fig. 3: Surface heat transfer profile for the $1^{\text {st }}$ section

The heat transfer results are shown (Fig. $3 \& 4$ ) with the surface temperature distribution taken from the $1^{\text {st }}$ and $4^{\text {th }}$ section of the CFD model, which involves the tubes and fin temperature distributions. 


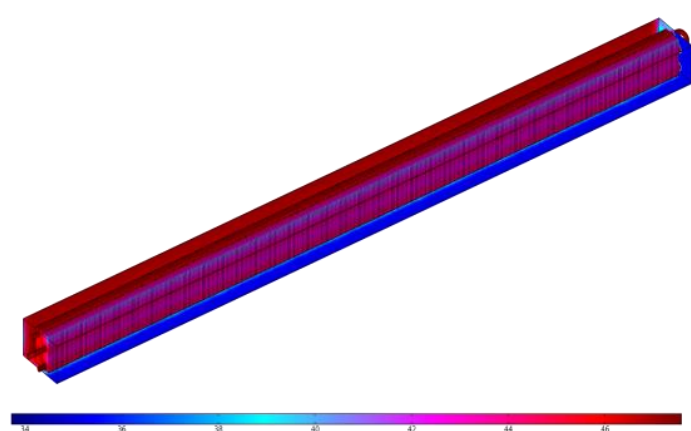

Fig. 4: Surface heat transfer profile for the $4^{\text {th }}$ section

At the end of the first section the refrigerant reaches to its saturation zone more specifically a little lower temperature from its gaseous zone considered in this model. To avoid two phase and latent heat complexity this little temperature interference was neglected. All the six sections were in the saturation zone except the last section. In this section a portion of the last tube among the four tubes were in subcooled region a very little.

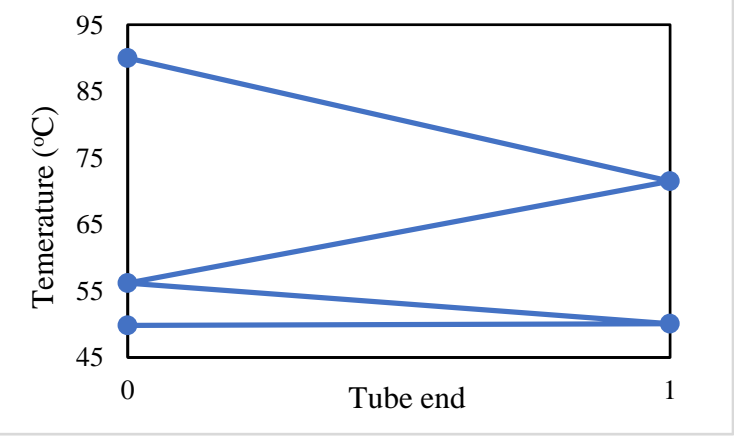

Fig. 6: Temperature profile for $1^{\text {st }}$ section

The temperature profile each section is almost similar (Fig. 6) in nature for the saturation zone sections except the first section (Fig 5).

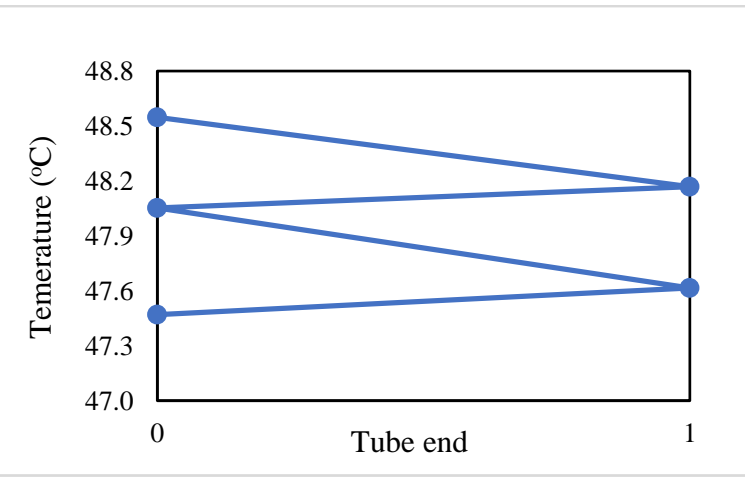

Fig. 8: Temperature profile for $4^{\text {th }}$ section

The first section has different trend as it transfers heat in the gas phase initially at a high temperature. The gas phase specific heat $(\mathrm{Cp})$ is a function of temperature. But as the gas is initially at a high temperature it transfers a high amount of heat. As it reaches to the saturation zone the slope of temperature fall decreases very slow. The temperature reduction from second to the last section gradually decreases as the next section has a lower refrigerant temperature than the previous one. In the first section the temperature reduction is very rapid initially and then gradually lessens. Ambient cold air flows without any temperature change until it comes to the heat exchanger and starts to become hotter while passing between the heat exchanger's fins and tubes. The frontal tubes are indicated by tube no 1 and 3 and the backside tubes are indicated as 2 and 4 for each section (Fig. 7). Refrigerant follows the path from tube no 1 to 4 through 2 and 3 respectively. For each section the temperature of the refrigerant falls from tube no 01 to 04 thoroughly. Most of the heat was transferred in the frontal area as the cold ambient temperature comes contact with the condenser.

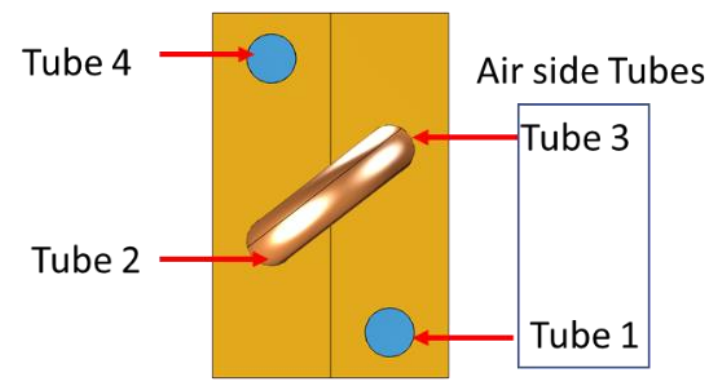

Fig. 5: Tube setup

Though tube 02 is hotter than tube 03 , the heat transfer is higher in tube 03 and its corresponding fin area because of cold air. The driving force i.e. temperature gradient in this area is high, so the heat

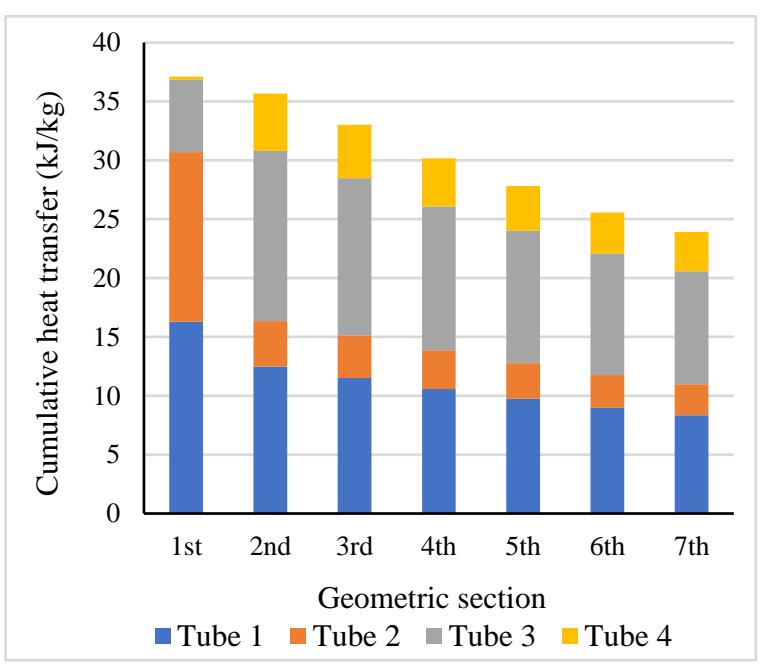

Fig. 7: Cumulative heat transfer in different geometric sections.

transfer is high also. The frontal area of each section is colder than the back portion (Fig 3 and 4) as it is in contact with cold air. Upper frontal edge of each section is showing the last temperature zone. It is 
because the position of the hot refrigerant containing tubes. The lower frontal area shows a higher temperature for the same reason. In practice for whole modeled together with the temperature distribution would have been as the area between tube 1 and 3. Both upper frontal of a section and lower frontal area of the next sections together nullify the effect of this boundary.

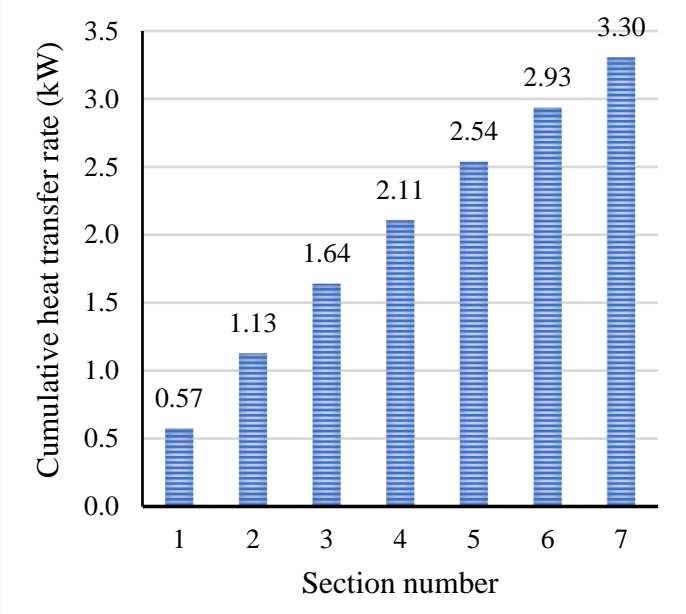

Fig. 9: Cumulative heat transfer rate plot

The similar statement is also applicable for the back area where the upper zone and lower zone is not representing the effect of the previous and the next sections. But when the sections' overall heat transfer is considered they nullify each other and gives reasonable result. Same as the temperature profile, heat transfer per tube pass also showed similar situation (Fig. 8). For second to the last section the trend is similar while a different one for the first section. Most of the heat transfer occurred in the saturation zone. The cumulative heat transfer (Fig. 9) increased but with slower rate for the forwarding sections.

This is because of the reduction in temperature gradient. The total cumulative heat transfer for the seven sections was $3.305 \mathrm{~kW}$. According to the symmetrical assumption of the geometry and other conditions, the upper symmetrical section/part will have same heat load making the total heat transfer to $6.61 \mathrm{~kW}$ for the whole condenser. The model was done for 1.5 ton RAC condenser. 1.5 ton is equivalent to $5.275 \mathrm{~kW}$. The condenser will include the work done by the compressor and the cooling capacity. The total power rating for 1.5 ton RAC was $1.7 \mathrm{~kW}$ and compressor duty was about to $1.6 \mathrm{~kW}$, obtained by excluding the power required for indoor and outdoor fans. This results in the heat duty of condenser as $6.875 \mathrm{~kW}$ where the result of the model differs from this value by less than $4 \%$.

\section{Conclusion}

In this study, a 3D CFD model was developed for a more complex geometry to determine the temperature distribution of a RAC outdoor unit condenser. Although SACs have been studied both numerically and experimentally in the past, this is the first/one of the earliest studies that examined heat transfer in 3D CFD model. Validation of model was made using real industrial data provided by a local AC manufacturer.

The numerical studies were performed for idealized situations. Some changes in the assumptions and finer mesh can be chosen to have more accuracy in the results. Radiative heat transfer could be taken into consideration. Effect of solar radiation on the condenser was not considered for this model. Computational assumptions and errors, as well as manufacturing and assembly defects, variable environmental conditions (rain, fog etc.) cannot be taken into consideration. The method developed in this study is a good tool for designing not only RACs but also other devices that have FTHEs.

\section{Acknowledgements}

This work was supported by Bangladesh University of Engineering and Technology and Elite Hitech Industry Ltd. We gratefully acknowledge their support.

\section{References}

[1] K. Sumeru, S. Sulaimon, F. N. Ani, and H. Nasution, "Numerical Study of an Ejector as an Expansion Device in type Air Conditioners Conditioner for Energy Savings," Appl. Mech. Mater., vol. 45, no. 2, pp. 179-192, 2013, doi: 10.5614/j.eng.technol.sci.2013.45..2.6.

[2] A. Avara and E. Daneshgar, "Optimum placement of condensing units of split-type air-conditioners by numerical simulation," Energy Build., vol. 40, pp. 1268-1272, 2008, doi: 10.1016/j.enbuild.2007.11.011.

[3] D. Kumlutas, Z. H. Karadeniz, and F. Kuru, "Investigation of $\mathrm{fl}$ ow and heat transfer for a split air conditioner indoor unit Dilek Kumlutas," Appl. Therm. Eng., vol. 51, pp. 262-272, 2013, doi: 10.1016/j.applthermaleng.2012.08.051.

[4] T. T. Chow, Z. Lin, and X. Y. Yang, "Placement of condensing units of split-type air-conditioners at low-rise residences," Appl. Therm. Eng., vol. 22, pp. 1431-1444, 2002.

[5] W. Zhang, Z. Yang, X. Zhang, D. Lv, and N. Jiang, "Experimental research on the explosion characteristics in the indoor and outdoor units of a 
split air conditioner using the R290 Recherche expérimentale des caractéristiques d' explosion des unités intérieures et extérieures d' un conditionneur d' air ," Int. J. Refrig., vol. 67, pp. 408-417, 2016, doi: 10.1016/j.ijrefrig.2016.03.018.

[6] X. Zhao, J. Sun, and Z. Zhang, "Prediction and measurement of axial flow fan aerodynamic and aeroacoustic performance in a split-type airconditioner outdoor unit ' visions et mesures de la performance ae 'rodynamique et Pre 'roacoustique du ventilateur axial d' un syste 'me exte '," Int. J. Refrig., vol. 36, no. 3, pp. 1098-1108, 2012, doi: 10.1016/j.ijrefrig.2012.11.024

[7] J. Hu and G. Ding, "Effect of deflecting ring on noise generated by outdoor set of a split-unit air conditioner 'ne ' re ' par un syste 'me de conditionnement d' air de type split: Bruit ge ' viation sur la re ' duction du bruit impact d ' un anneau de de," Elsevier Sci., vol. 29, pp. 505-513, 2006, doi: 10.1016/j.ijrefrig.2005.07.002.

[8] N. Mendes, "Empirical modeling of room air conditioners for building energy analysis," Energy Build., vol. 47, pp. 19-26, 2012, doi: 10.1016/j.enbuild.2011.11.012.

[9] H. Chen, W. L. Lee, and F. W. H. Yik, "Applying water cooled air conditioners in residential buildings in Hong Kong," Energy Convers. Manag., vol. 49, pp. 1416-1423, 2008, doi: 10.1016/j.enconman.2007.12.024.

[10] G. Zhou and Y. Zhang, "Performance of a split-type air conditioner matched with coiled adiabatic capillary tubes using HCFC22 and HC290," Appl. Energy, vol. 87, no. 5, pp. 1522-1528, 2010, doi: 10.1016/j.apenergy.2009.10.005.
[11] T. T. Chow, Z. Lin, and J. P. Liu, "Effect of condensing unit layout at building re-entrant on splittype air-conditioner performance," Energy Build., vol. 34, pp. 237-244, 2002

[12] Y. Zhu, X. Jin, Z. Du, B. Fan, and X. Fang, "Simulation of variable refrigerant flow air conditioning system in heating mode combined with outdoor air processing unit," Energy Build., vol. 68, pp. 571-579, 2014, doi: 10.1016/j.enbuild.2013.09.042.

[13] Y. H. Yau and H. L. Pean, "The performance study of a split type air conditioning system in the tropics , as affected by weather," Energy Build., vol. 72, no. 2014, pp. 1-7, 2020, doi: 10.1016/j.enbuild.2013.12.010.

[14] E. M. Barreira, C. O. R. Negrão, and C. J. L. Hermes, "Thermoeconomic analysis and optimization of residential split-type air conditioners," Appl. Therm. Eng., vol. 50, no. 1, pp. 629-636, 2013, doi: 10.1016/j.applthermaleng.2012.06.006.

[15] S. A. Nada and M. A. Said, "Performance and energy consumptions of split type air conditioning units for different arrangements of outdoor units in confined building shafts," Appl. Therm. Eng., vol. 123, pp. 874-890, 2017, doi: 10.1016/j.applthermaleng.2017.05.104.

[16] F. Moukalled, S. Verma, and M. Darwish, "The use of CFD for predicting and optimizing the performance of air conditioning equipment," Int. J. Heat Mass Transf., vol. 54, no. 1-3, pp. 549-563, 2011, doi: 10.1016/j.ijheatmasstransfer.2010.09.015.

[17] T. J. Chung, Computational fluid dynamics, second edition, vol. 9780521769.2010.

(CBangladesh Uni. of Engg. \& Tech. 